\title{
Prognostic significance of K-ras mutations in pancreatic cancer: a meta-analysis
}

\author{
Lian-yuan Tao, Ling-fu Zhang, Dian-rong Xiu*, Chun-hui Yuan, Zhao-lai Ma and Bin Jiang
}

\begin{abstract}
Background: K-ras gene mutations are common in patients with pancreatic cancer (PC); however, their prognostic value for PC remains inconclusive. This meta-analysis was performed to quantitatively evaluate the association between K-ras mutations and survival in patients with pancreatic cancer.

Methods: We performed a comprehensive search of electronic sources including MEDLINE (via PubMed), Web of Science, and the Cochrane Library. The search covered a publication period from inception to November 2015.

Results: Seventeen studies with a total of 2249 patients with pancreatic cancer were included in the tissue detection of this study. The meta-analysis indicated a significant association between mutant K-ras genes and overall survival (OS) $(\mathrm{HR}=1.51,95 \% \mathrm{Cl} 1.32-1.72, P<0.001)$. Moreover, further subgroup analyses by ethnicity, publication year, therapy method, cancer resectability, and gene detection method all revealed that pancreatic cancer patients with the K-ras mutation had significantly poorer OS $(P<0.05)$. And results from four studies with 225 patients focused on plasma K-ras mutations enhanced such association ( $\mathrm{HR}=2.23,95 \% \mathrm{Cl} 1.69-2.95, P<0.001)$.
\end{abstract}

Conclusions: As a prediction of poor prognosis, the detection of K-ras mutations may be a useful prognostic factor for pancreatic cancer patients.

Keywords: K-ras, Pancreatic cancer, Prognosis, Meta-analysis

\section{Core tip}

To our knowledge, this is the first meta-analysis of all eligible studies on the prognostic role of the K-ras mutation in patients with pancreatic cancer. In populations of both Caucasian and Asian descent, patients with pancreatic cancer harboring K-ras mutations tend to get a worse survival. K-ras mutations may represent a useful prognostic factor to stratify patients with high risk and develop specific treatments for these patients in clinical applications.

\section{Background}

Pancreatic cancer (PC) has a 5-year survival rate of less than $5 \%$, is one of the most aggressive malignancies, and represents a leading cause of cancer-related mortality $[1,2]$. Most patients were diagnosed when they got jaundice, and imaging examination was the most effective diagnosis tool; however, those patients may get an

\footnotetext{
* Correspondence: xiudianrong123@sina.com

Department of General Surgery, Peking University Third Hospital, No. 49, Hua Yuan North Rd, Hai Dian District, Beijing 100191, China
}

advanced stage and even lost the opportunity for operation, as operation is still the only effective treatment for PC. What is more, even patients received a curative operation, the prognosis is still unsatisfactory.

As a member of the Ras gene family, K-ras plays a key role in Ras/mitogen-activated protein kinase signaling. Somatic mutation in K-ras mutations have been shown to be early events in the carcinogenesis of human pancreatic cancer [3, 4]. Approximately $80 \%$ of K-ras mutations in pancreatic cancer involve codon 12; others are located in codons 13, 61, and 1 [5-7]. K-ras mutations have been demonstrated to enhance cellular proliferation and induce malignant transformation, and their continuous activation played a key role in the development and maintenance of pancreatic cancer [8].

Recent meta-analyses have suggested that K-ras mutations can be used as useful biomarkers for the early detection of pancreatic cancer $[9,10]$. It has been reported positive in about $65 \%$ patients with PC. Although it expressed in most pancreatic cancer patients, a sensitivity of $65 \%$, sometimes even lower to $36 \%$, limits its diagnosis 
application $[9,10]$. However, its application in the predication of prognosis and guidance of treatment may be much more valuable. Although many recent studies evaluated K-ras gene mutations that appeared to influence the prognosis and patterns of gene expression [11, 12], the use of K-ras mutations as a prognostic factor for pancreatic cancer remains inconclusive. To clarify the role of $\mathrm{K}$ ras mutations in the prognosis of pancreatic cancer, we performed the present comprehensive meta-analysis. The detection sources could be tissues or plasma, we tend to explore both of the sources respectively. To our knowledge, this study was the first meta-analysis of all eligible studies on the prognostic role of the K-ras mutation in patients with pancreatic cancer.

\section{Methods}

\section{Literature search}

A systematic literature search was carried out in MEDLINE (via PubMed), Web of Science, and the Cochrane Library to screen for cohort/case-control studies characterizing the association between K-ras mutation and prognosis in PC patient. The search terms were pancreatic or pancreas neoplasms, ras or K-ras gene, survival, and prognosis, which covered the publication period from inception to November 2015. The meta-analysis was performed using the STATA statistical software. Review articles were also screened to search for relevant original studies. Only articles published in English were included in our meta-analysis.

\section{Study selection criteria}

Studies deal with the comparison between PC patient with and without K-ras mutation fulfilling the following criteria were considered to satisfy the inclusion criteria of present study: (1) cohort studies, nested case-control studies, or case-control studies focusing on the prognostic value of K-ras mutant type in patients with pancreatic cancer; (2) gene amplification status of K-ras was detected in surgical or plasma specimens; (3) all patient diagnoses of pancreatic cancer were confirmed through histopathologic detection; (4) sufficient data were provided to calculate hazard ratios (HR) for OS comparing mutant K-ras with wild-type K-ras patients; and (5) more than ten patient samples with K-ras mutation were included in the original studies because small sample size may be vulnerable to selection bias. If more than one study by the same authors (using the same case series) was published, the study with the largest sample size was included. The data collected from surgical tissues and plasma specimens were divided in two different groups and analyzed, respectively.

\section{Data extraction and methodological quality assessment} Two reviewers (LY Tao and LF Zhang) firstly screened the titles and/or abstracts of all articles independently; we resolved cases with any disagreements through discussion and careful reexaminations. The following variables from studies were extracted with a pre-designed spreadsheet: first author, year of publication, source of publication, country, patients' ethnicity, study design, total number of cases, detection method of K-ras expression, mutated sites, treatment method, and OS. Quality assessment of the included studies was conducted based on the Newcastle-Ottawa Scale (NOS) criteria (targeting the quality of non-randomized studies) [13]. The NOS criteria apply a "star" rating system ranges from 0 (worst) to 8 (best) for the judgment of methodological quality, which was based on selection, comparability, and outcome. We set 5 star as the cutoff value of our analysis, as article with NOS $\geq 5$ was qualified enough for a meta-analysis. Conflicting evaluations or inconsistent data from the eligible studies were resolved through discussion or by asking a verdict by a third arbitrator (DR Xiu).

\section{Statistical analysis}

The effects of K-ras gene mutations on OS were assessed using the overall $\mathrm{HR}$ and $95 \%$ confidence interval (95\% CI). Data from Kaplan-Meier survival curves were collected through Engauge Digitizer version 4.1 (free software downloaded from http://sourceforge.net) when the HR was not provided, and the minimum and maximum follow-up periods were obtained from the articles. Heterogeneity between studies was estimated using both the Cochran's Q statistic (which considered significant at $P<0.10$ [14]). A fixed effects model (the Mantel-Haenszel method) was used for the calculation of Crude HRs when there was no statistically significant heterogeneity $(Q$ test with $P>0.10$ ). Otherwise, the random effects model (the DerSimonian Laird method) was conducted. The significance of the pooled estimate was determined using the $Z$ test.

Subgroup analyses were performed based on ethnicity, publication years, detection methods, tumor resectability, and treatment methods. Besides, a sensitivity analysis was performed using the sequential omission of individual studies to assess the quality and consistency of the results. Begg's funnel plots were also constructed to evaluate the effect of publication bias on this study, and Egger's linear regression test was further performed to evaluate the symmetry of these funnel plots [15]. All meta-analyses were calculated using Stata software 12.0 (Stata Corp LP, College Station, TX, USA). All tests were two-sided with $P<0.05$ as statistically significant.

\section{Results}

\section{Description and quality assessment of studies}

A total of 1147 studies meeting the search strategy were initially identified, and 699 duplicates were excluded, leaving 448 articles. After a review of their titles and abstracts, 387 articles were excluded. Another 61 articles 
were excluded after full text identification, leaving 17 studies for tissues detection and 4 studies for plasma detection that met our criteria for this meta-analysis (Fig. 1). As for tissue detection, a total of 2249 (1302 males and 947 females) pancreatic cancer patients, including 1261 patients in the K-ras mutant group and 988 patients in the wildtype group, were involved in present meta-analysis. A summary of the characteristics and methodological quality of the included studies are shown in Table 1. Four studies with a total of 225 patients were included in the analysis of plasma detection, which are listed in Table 2.

\section{Quantitative data synthesis}

The meta-analysis results suggested that K-ras gene mutations were significantly associated with poorer OS $(\mathrm{HR}=1.51,95 \%$ CI 1.32-1.72, $P<0.001$; $P$ for heterogeneity 0.62 , fixed effects model) (Fig. 2). HRs for OS comparing the K-ras mutant type group with the wildtype group is summarized in Table 3.
Results from a subgroup analysis by ethnicity indicated that K-ras mutant patients had poorer OS among both Caucasia and $n$ Asian populations (HR $=1.35,95 \% \mathrm{CI}$ $1.10-1.64, P=0.000 \%$ and $\mathrm{HR}=1.65,95 \%$ CI $1.38-1.97$, $P<0.001$, respectively; both $P$ for heterogeneity $>0.1$, fixed effects models). Because the publication number of K-rasrelated articles focus on pancreatic cancer was elevated significantly after 2010, we chose the year of 2010 as a cutoff point. The further stratified analyses by publication year suggested that, despite no significant association between K-ras mutation and OS prior to 2010, which included the year of 2010 (HR $=1.27,95 \%$ CI 0.96-1.69, $P=0.098 ; P$ for heterogeneity $>0.1$, fixed effects model), the K-ras mutant patients had worse OS than the patients without K-ras mutations after $2010(\mathrm{HR}=1.58,95 \% \mathrm{CI}$ 1.36-1.83, $P<0.001 ; P$ for heterogeneity $>0.1$, fixed effects model). With the exception of the study by Kinugasa $\mathrm{H}$ [28], which failed to provide detailed information about the treatment, subgroup analyses by the respectability

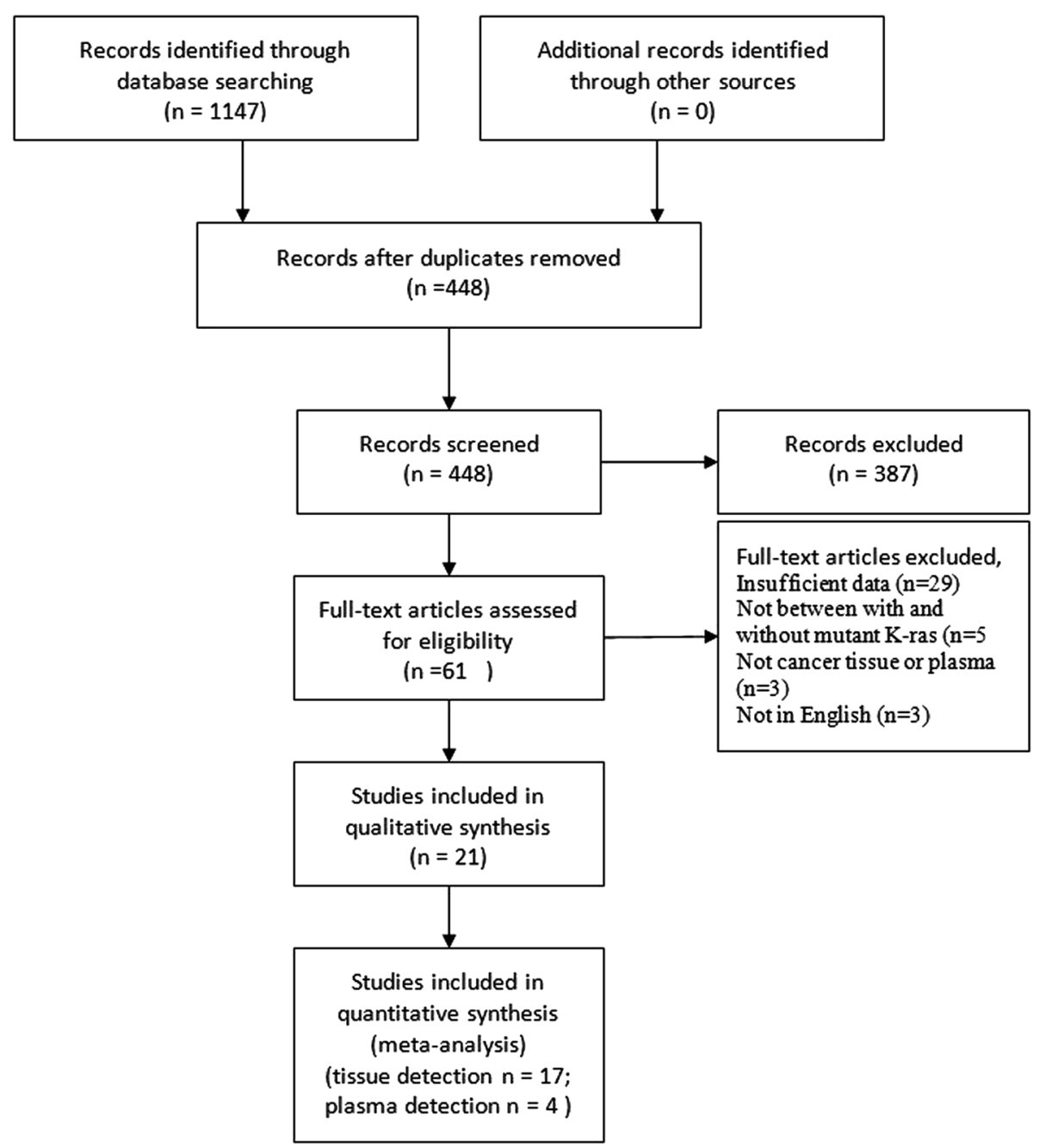

Fig. 1 Flowchart of the search history in this meta-analysis 
Table 1 Characteristic summary of studies included in the meta-analysis

\begin{tabular}{|c|c|c|c|c|c|c|c|c|c|}
\hline The author & Year & Country & Ethnicity & Age (years) & Gender (M/F) & Treatment & Detection method & Outcome & NOS \\
\hline Allison, D.C. [16] & 1998 & USA & Caucasians & $63(32-80)$ & $40 / 36$ & Operation & $\begin{array}{l}\text { Enriched PCR and } \\
\text { oligonucleotide } \\
\text { hybridization }\end{array}$ & OS & 6 \\
\hline Boeck, S [17] & 2013 & Germany & Caucasians & $64(32-78)$ & $105 / 68$ & Chemotherapy & Pyrosequencing & OS & 7 \\
\hline Kim, S.T. [18] & 2011 & Korea & Asians & $\begin{array}{l}\geq 60, n=84 \\
<60, n=52\end{array}$ & $99 / 37$ & Chemotherapy & DS & OS & 7 \\
\hline Ogur, T [19] & 2014 & Japan & Asians & $65(35-84)$ & $146 / 96$ & Chemotherapy & RT-PCR & OS & 6 \\
\hline Schultz, N.A. [6] & 2012 & Denmark & Caucasians & $63(33-85)$ & $88 / 82$ & Operation & DS & OS & 7 \\
\hline Shin, S.H. [20] & 2013 & Korea & Asians & $60(22-78)$ & $139 / 95$ & Operation & PCR-RFLP & OS & 8 \\
\hline Sinn, B.V. [7] & 2014 & Germany & Caucasians & $\begin{array}{l}\geq 65, n=81 \\
<65, n=72\end{array}$ & $84 / 69$ & Operation & DS & OS & 7 \\
\hline Franko, J [21] & 2008 & USA & Caucasians & $68 \pm 12$ & $26 / 24$ & $\begin{array}{l}\text { Operation and } \\
\text { chemotherapy }\end{array}$ & DS & OS & 6 \\
\hline $\begin{array}{l}\text { Da Cunha Santos, } \\
\text { G [22] }\end{array}$ & 2010 & Canada & Caucasians & $62(40-85)$ & $64 / 53$ & Chemotherapy & $\mathrm{PCR}$ and $\mathrm{BS}$ & OS & 7 \\
\hline Fensterer, H [5] & 2013 & Germany & Caucasians & 62.7 & $36 / 30$ & $\begin{array}{l}\text { Operation and } \\
\text { chemotherapy }\end{array}$ & $\begin{array}{l}\text { High-resolution melting } \\
\text { assay }\end{array}$ & OS & 6 \\
\hline Ikeda, N [23] & 2001 & Japan & Asians & $63.7(47-80)$ & $37 / 11$ & $\begin{array}{l}\text { Operation and } \\
\text { chemotherapy }\end{array}$ & DS & OS & 7 \\
\hline Kwon, M.J. [24] & 2011 & Korea & Asians & $63(45-86)$ & $37 / 35$ & $\begin{array}{l}\text { Operation and } \\
\text { chemotherapy }\end{array}$ & RT-PCR & OS & 8 \\
\hline Lee, J [25] & 2007 & Korea & Asians & $\begin{array}{l}\geq 60, n=47 \\
<60, n=19\end{array}$ & $51 / 15$ & Chemotherapy & DS & OS & 5 \\
\hline Oh, D.Y. [26] & 2012 & Korea & Asians & $57.3(39-77)$ & $24 / 16$ & Chemotherapy & DS & OS & 6 \\
\hline Salek, C [27] & 2009 & Czech & Caucasians & $\begin{array}{l}63 \pm 10.5 \\
(40-84)\end{array}$ & $28 / 25$ & Chemotherapy & GenoScan & OS & 6 \\
\hline Kinugasa, H [28] & 2015 & Japan & Asians & $66(47-85)$ & $54 / 21$ & NR & Digital PCR & OS & 7 \\
\hline $\begin{array}{l}\text { Talar-Wojnarowska, } \\
\text { R [29] }\end{array}$ & 2005 & Poland & Caucasians & $47-76$ & $10 / 16$ & Operation & PCR-RFLP & OS & 6 \\
\hline
\end{tabular}

$D S$ direct sequencing, $B S$ bidirectional sequencing, NR not reported, $R T-P C R$ reverse transcription polymerase chain reaction, $P C R-R F L P$ polymerase chain reactionrestriction fragment length polymorphism, NOS Newcastle-Ottawa Scale (NOS) criteria (targeting the quality of non-randomized studies)

(those who underwent an operation) of cancer indicated that K-ras mutant patients had worse OS whether the cancers were resectable or not $(\mathrm{HR}=1.44,95 \% \mathrm{CI} 1.19-1.74$, $P<0.001$ and $\mathrm{HR}=1.57,95 \%$ CI $1.30-1.91, P<0.001$, respectively; both $P$ for heterogeneity $>0.1$, fixed effects models). Additionally, the subgroup analysis according to treatment methods revealed a statistically significant difference in OS between the K-ras gene mutant group and the wild-type group (operation only: $\mathrm{HR}=1.35,95 \% \mathrm{CI}$ $1.09-1.69, P=0.005 \%$; chemotherapy only: $\mathrm{HR}=1.57$, $95 \%$ CI 1.30-1.91, $P<0.001$; operation and chemotherapy: $\mathrm{HR}=1.71,95 \% \mathrm{CI} 1.18-2.48, P=0.005$, respectively; All $P$ for heterogeneity $>0.1$, fixed effects models). Finally, a subgroup analysis according to gene detection methods also showed that the K-ras gene mutation was significantly associated with poorer OS (HR $=1.46,95 \%$ CI 1.22-1.75,

Table 2 Characteristic summary of studies that detected the K-ras gene in plasma

\begin{tabular}{llllllllll}
\hline Author & Year & Country & Ethnicity & Age (years) & Gender (M/F) & K-ras (mutant/wild) & HR (95 \% Cl) & Outcome & Sites \\
\hline Kinugasa, H [28] & 2015 & Japan & Asians & $66(47-85)$ & $54 / 21$ & $47 / 28$ & $1.84(1.1-3.25)$ & OS & $12,13,61$ \\
Castells, A [12] & 1999 & Spain & Caucasian & NR & NR & $12 / 32$ & $1.51(1.02-2.23)$ & OS & 12 \\
Chen, H.H. [30] & 2010 & China & Asians & $60(37-78)$ & $57 / 34$ & $30 / 61$ & $7.39(3.7-14.9)$ & OS & 12 \\
Yadama, T [31] & 1998 & Japan & Asians & $63.9(35-78)$ & $11 / 4$ & $11 / 4$ & $4.7(2.8-21.2)$ & OS & 12 \\
Combined & & & & & & & $2.23(1.69-2.95)$ & OS \\
\hline
\end{tabular}




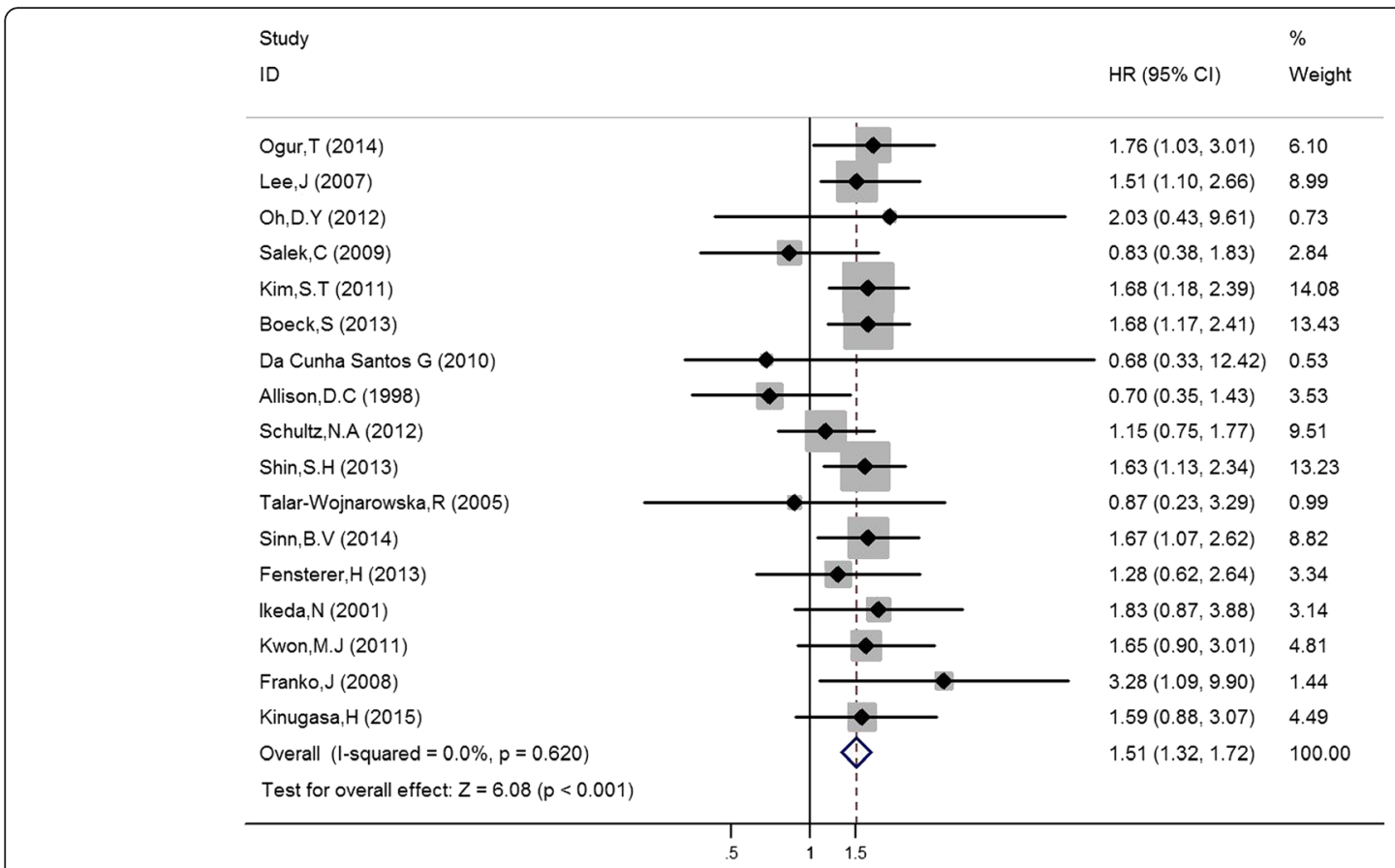

Fig. 2 Forest plots for the relationships between K-ras gene mutations and prognosis in patients with pancreatic cancer

$P<0.001$ and $\mathrm{HR}=1.57,95 \%$ CI $1.29-1.90, P=0.005$, respectively; $P$ for heterogeneity $>0.1$, both fixed effects models) (Table 4).

To further evaluate the prognostic value of $\mathrm{K}$-ras mutations in pancreatic cancer, we listed characteristics from the four studies that focused on the relationship between plasma K-ras mutations and pancreatic cancer prognosis [12, 28, 30, 31]. K-ras mutations in all four studies revealed a significant association with poorer OS, and the combined $\mathrm{HR}$ also indicated a strong association $(\mathrm{HR}=2.23,95 \%$ CI $1.69-2.95, P<0.001 ; P$ for heterogeneity $<0.1$, random effects model), (Table 2 ).

Table 3 The hazard ratios for overall survival comparing K-ras mutations with the wild-type in the included studies

\begin{tabular}{|c|c|c|c|c|c|}
\hline The author & Year & K-ras (mutant/wild) & $\mathrm{HR}(95 \% \mathrm{Cl})$ & $P$ value & Sites \\
\hline Allison, D.C. [16] & 1998 & $64 / 12$ & $0.70(0.35-1.43)$ & 0.330 & NR \\
\hline Boeck, S [17] & 2013 & $121 / 52$ & $1.68(1.17-2.41)$ & 0.005 & 12,13 \\
\hline Kim, S.T [18] & 2011 & $71 / 65$ & $1.68(1.18-2.39)$ & 0.001 & 12,13 \\
\hline Ogur, T [19] & 2014 & $214 / 28$ & $1.76(1.03-3.01)$ & 0.040 & 12 \\
\hline Schultz, N.A. [6] & 2012 & $136 / 34$ & $1.15(0.75-1.77)$ & 0.510 & $12,13,61$ \\
\hline Shin, S.H. [20] & 2013 & 126/108 & $1.63(1.13-2.34)$ & 0.001 & 12,13 \\
\hline Sinn, B.V. [7] & 2014 & $105 / 48$ & $1.68(1.07-2.62)$ & 0.023 & $12,13,61$ \\
\hline Franko, J [21] & 2008 & $31 / 19$ & $3.28(1.09-9.90)$ & 0.035 & $12,13,1$ \\
\hline da Cunha Santos, G [22] & 2010 & $92 / 25$ & $0.68(0.33-12.42)$ & 0.300 & 12,13 \\
\hline Fensterer, H [5] & 2013 & $45 / 21$ & $1.28(0.62-2.64)$ & 0.180 & 12,13 \\
\hline Ikeda, N [23] & 2001 & $33 / 15$ & $1.83(0.87-3.88)$ & 0.317 & 12 \\
\hline Kwon, M.J. [24] & 2011 & $34 / 38$ & $1.65(0.90-3.01)$ & 0.159 & $12,13,1$ \\
\hline Lee, J [25] & 2007 & $33 / 33$ & $1.51(1.01-2.66)$ & 0.030 & 12 \\
\hline Oh, D.Y. [26] & 2012 & $19 / 21$ & $2.03(0.43-9.61)$ & 0.158 & 12,13 \\
\hline Salek, C [27] & 2009 & $36 / 17$ & $0.83(0.38-1.83)$ & 0.636 & 12,13 \\
\hline Kinugasa, H [28] & 2015 & $47 / 28$ & $1.59(0.88-3.07)$ & 0.124 & $12,13,61$ \\
\hline Talar-Wojnarowska, R [29] & 2005 & $20 / 6$ & $0.87(0.23-3.29)$ & 0.580 & 12 \\
\hline
\end{tabular}


Table 4 Subgroup analysis of the association between K-ras mutations and overall survival of patients with pancreatic cancer

\begin{tabular}{|c|c|c|c|c|c|}
\hline Subgroup & $\begin{array}{l}\text { No. of patients with } \\
\text { mutant K-ras }\end{array}$ & $\begin{array}{l}\text { No. of patients without } \\
\text { mutant K-ras }\end{array}$ & HR $(95 \% \mathrm{Cl})$ & Heterogeneity $R^{2}(\%)$ & $\begin{array}{l}\text { Heterogeneity } \\
P \text { value }\end{array}$ \\
\hline \multicolumn{6}{|l|}{ Ethnicity } \\
\hline Caucasian & 650 & 234 & $1.35(1.10-1.63)$ & 28.0 & 0.195 \\
\hline Asian & 586 & 327 & $1.65(1.32-1.72)$ & 0.0 & 0.136 \\
\hline \multicolumn{6}{|l|}{ Publication year } \\
\hline Before 2010 & 309 & 127 & $1.27(0.96-1.69)$ & 33.1 & 0.175 \\
\hline After 2010 & 927 & 434 & $1.58(1.36-1.83)$ & 0.0 & 0.963 \\
\hline \multicolumn{6}{|l|}{ Tumor resectability } \\
\hline Resectable & 594 & 301 & $1.44(1.19-1.74)$ & 14.3 & 0.315 \\
\hline Unresectable & 586 & 241 & $1.57(1.30-1.91)$ & 0.0 & 0.686 \\
\hline \multicolumn{6}{|l|}{ Treatment } \\
\hline Operation & 451 & 208 & $1.35(1.09-1.69)$ & 35.7 & 0.183 \\
\hline Chemotherapy & 586 & 241 & $1.57(1.30-1.91)$ & 0.0 & 0.686 \\
\hline Operation + chemotherapy & 143 & 93 & $1.71(1.18-2.48)$ & 0.0 & 0.574 \\
\hline \multicolumn{6}{|l|}{ Detection methods } \\
\hline Sequencing & 428 & 235 & $1.57(1.29-1.90)$ & 0.0 & 0.644 \\
\hline Other methods & 808 & 326 & $1.46(1.22-1.75)$ & 2.0 & 0.421 \\
\hline
\end{tabular}

\section{Evaluation of heterogeneity and publication bias}

The results of the sensitivity analysis suggested that no individual studies significantly affected the pooled HRs (Fig. 3). The shapes of Begg's funnel plots and the result of Egger's linear regression test $(P=0.356)$ did not reveal evidence of obvious publication bias (Fig. 4).

\section{Discussion}

In our work, the combined HR for 17 studies evaluating the correlation between K-ras mutations and overall survival of patients with pancreatic cancer was 1.51 (95\% CI 1.32-1.72, $P=0.000)$, which indicated that $K$-ras mutations have negative prognostic value in pancreatic cancer. In our subgroup analyses, the HR for both Caucasian and Asian populations implied that pancreatic cancer patients harboring K-ras mutations also tend to get a worse survival. Furthermore, subgroup analyses according to tumor resectability and the treatment and detection methods of K-ras still revealed that K-ras gene mutations were strongly correlated with poorer prognoses in patients with pancreatic cancer. Notably, the K-ras mutation was only significantly correlated with poorer OS after 2010 (not included 2010). However, the combined HR of K-ras mutation before is 1.27 , which still

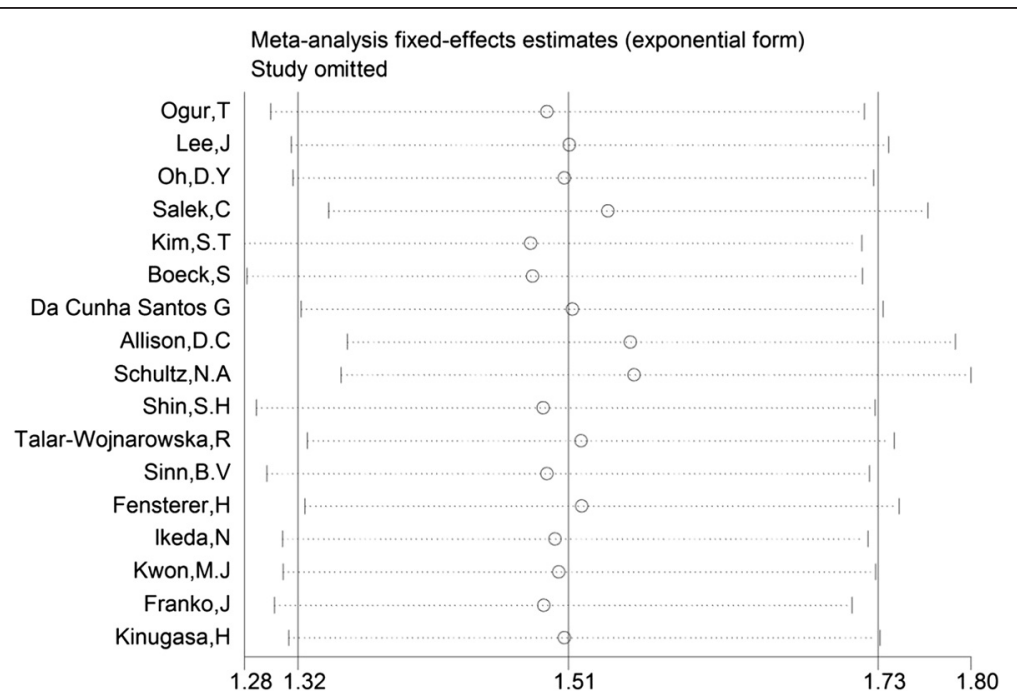

Fig. 3 Sensitivity analysis for the pooled HRs of the differences in OS between K-ras gene mutations and wild-type pancreatic patients 
Begg's funnel plot with pseudo $95 \%$ confidence limits

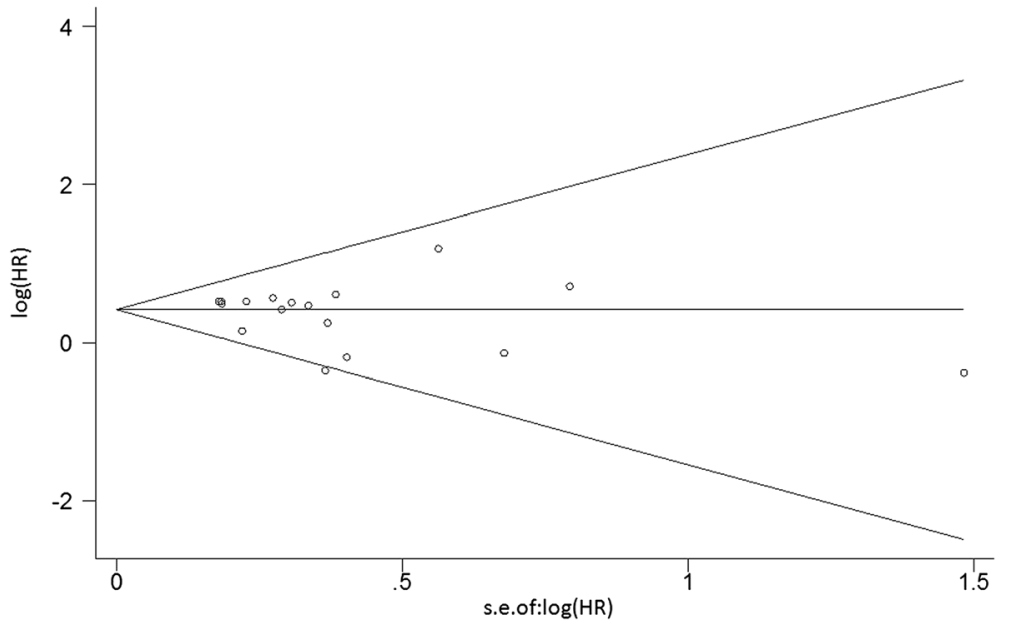

Fig. 4 Begg's funnel plots of the prognostic role of K-ras gene mutations in pancreatic cancer patients. Each point represents a separate study for the indicated association. $\log (\mathrm{HR})$ natural logarithm of HR; horizontal line means the magnitude of the effect. Note: A funnel plot with 95\% confidence limit was used (Egger's test: $t=-0.95, P=0.356$ )

supports our conclusion. The reason why the insignificant association may be the small sample sizes of the studies.

Detection of K-ras mutations in circulating DNA, which can be performed before and after operation, is much more convenient than the application of tissue samples. The occurrence or absence of K-ras mutations in the peripheral blood might reflect different tumor stages [32]. The detection of K-ras mutations in the peripheral blood could reflect the tumor burden of individual PC patients, and in turn predict a prognosis. During the analysis of plasma samples, all the four studies have a significant association between K-ras mutations and poorer OS, and a higher combined HR of 2.23 further agree with the prognostic value of mutant K-ras. All the data above demonstrated the feasibility of K-ras mutations as a predictor of prognosis of PC patients. It is of great significance to one of the most malignant tumor, which has a 5 -year survival rate of less than $5 \%$. For patients with expression of $\mathrm{K}$-ras mutations, more frequently postoperative re-examination and follow-up survey may be needed and more proactive therapeutic schedule of postoperative adjuvant therapy may be necessary when compared to the negative expressed patients.

Other than a useful prognosis predictor of pancreatic cancer, the detection of mutant K-ras may make it possible to develop new therapeutic approaches. As a member of the Ras gene family, K-ras plays a key role in Ras/mitogenactivated protein kinase signaling. Somatic mutation in Kras mutations have been shown to be early events in the carcinogenesis of human pancreatic cancer $[3,4]$. To blockade the Ras signaling pathway, it has been proposed that cancer vaccines that stimulate immunity against mutant Ras proteins and antisense therapy that blocks the translation of mutant Ras gene could be applied in the treatment after operation [33]. Evidence has indicated that $\mathrm{K}$-ras expression and the growth and invasiveness of PC cell lines can be inhibit by K-ras antisense oligodeoxynucleotide (K-ras-ASODN). Similar effects also can be identified in the models of PC by intraperitoneal injection of adenovirus [34].

This study has several limitations. First, current samples of available studies were relatively small with 17 for tissue detection and only 4 for plasma detection. However, such number is enough for a meta-analysis, and we even give a subgroup analysis of tissue detection studies. Second, the definition of resectability (between centers and surgeons) and the treatment after operation like chemotherapy may be different between the studies. Such limitation is hard to control for the treatment of pancreatic cancer is still under controversy. Lastly, data about tumor stage or sample size were not provided in most included articles, and the divide of stage for analysis was also not unified, which prevent a further subgroup analysis. Despite those shortcomings, the effect of K-ras on survival was consistent in nearly all of the included studies, and no studies reported a favorable outcome in patients with K-ras mutations.

\section{Conclusions}

In conclusion, K-ras gene mutations are associated with a poorer prognosis in patients with pancreatic cancer. It may represent a useful prognostic factor to stratify patients with high risk and in developing specific treatments for these patients in clinical applications. 


\section{Institutional review board statement}

\section{This study was approved by the Clinical Ethics Committee} of Peking University Third Hospital.

\section{Competing interests}

The authors declare that they have no competing interests.

\section{Authors' contributions}

DX and LT conceived and designed this study; LT and LZ searched the databases and collected the data; LT, DX, CY, ZM, and BJ performed the statistical analysis and interpretation of data; LT and DX wrote the manuscript. All authors read and approved the final manuscript.

\section{Acknowledgements}

The authors are grateful to Yufeng Yin and other related staff at the Peking University Third Hospital who helped with the study performance and data collection. We thank native English-speaking biologists who provided medical writing services on behalf of AJE publication service company.

\section{Funding}

This study was supported by a grant from the Doctoral Fund of the Ministry Education of China (No. 20090001110096).

Received: 11 December 2015 Accepted: 21 April 2016 Published online: 16 May 2016

\section{References}

1. Hidalgo M. Pancreatic cancer. N Engl J Med. 2010;362:1605-17.

2. Maisonneuve $P$, Lowenfels AB. Epidemiology of pancreatic cancer: an update. Dig Dis. 2010;28:645-56.

3. Agarwal A, Saif MW. KRAS in pancreatic cancer. JOP. 2014;15:303-5.

4. Maisonneuve $P$, Lowenfels AB. Risk factors for pancreatic cancer: a summary review of meta-analytical studies. Int J Epidemiol. 2015;44:186-98.

5. Fensterer $\mathrm{H}$, Schade-Brittinger $\mathrm{C}$, Muller $\mathrm{HH}$, et al. Multicenter phase II trial to investigate safety and efficacy of gemcitabine combined with cetuximab as adjuvant therapy in pancreatic cancer (ATIP). Ann Oncol. 2013:24:2576-81.

6. Schultz NA, Roslind A, Christensen IJ, et al. Frequencies and prognostic role of KRAS and BRAF mutations in patients with localized pancreatic and ampullary adenocarcinomas. Pancreas. 2012;41:759-66.

7. Sinn BV, Striefler JK, Rudl MA, et al. KRAS mutations in codon 12 or 13 are associated with worse prognosis in pancreatic ductal adenocarcinoma. Pancreas. 2014:43:578-83.

8. Yin $X$, Su J, Zhou $X$, et al. K-ras-driven engineered mouse models for pancreatic cancer. Discov Med. 2015;19:15-21.

9. Gu J, Wang D, Huang Y, et al. Diagnostic value of combining CA 19-9 and K-ras gene mutation in pancreatic carcinoma: a meta-analysis. Int J Clin Exp. 2014;7:3225-34

10. Liu SL, Chen G, Zhao YP, et al. Diagnostic accuracy of K-ras mutation for pancreatic carcinoma: a meta-analysis. Hepatobiliary Pancreat Dis Int. 2013, 12:458-64

11. Qin R, Smyrk TC, Reed NR, et al. Combining clinicopathological predictors and molecular biomarkers in the oncogenic K-RAS/Ki67/HIF-1alpha pathway to predict survival in resectable pancreatic cancer. Br J Cancer. 2015;112: 514-22.

12. Castells A, Puig P, Mora J, et al. K-ras mutations in DNA extracted from the plasma of patients with pancreatic carcinoma: diagnostic utility and prognostic significance. J Clin Oncol. 1999;17:578-84.

13. GA Wells SB, O'Connell D, Peterson J, Welch V, Losos M, Tugwell P. The Newcastle-Ottawa score for non-randomized studies. Available at: http://www.ohrica/programs/clinical_epidemiology/oxfordasp 2013; Accessed December 20, 2013.

14. Jackson D, White IR, Riley RD. Quantifying the impact of between-study heterogeneity in multivariate meta-analyses. Stat Med. 2012;31:3805-20.

15. Peters JL, Sutton AJ, Jones DR, et al. Comparison of two methods to detect publication bias in meta-analysis. JAMA. 2006:295:676-80.

16. Allison DC, Piantadosi S, Hruban RH et al. DNA content and other factors associated with ten-year survival after resection of pancreatic carcinoma. J Surg Oncol 1998;67:151-9.
17. Boeck S, Jung A, Laubender RP et al. EGFR pathway biomarkers in erlotinibtreated patients with advanced pancreatic cancer: translational results from the randomised, crossover phase 3 trial AIO-PK0104. Br J Cancer 2013;108:469-76.

18. Kim ST, Lim do H, Jang KT et al. Impact of KRAS mutations on clinical outcomes in pancreatic cancer patients treated with first-line gemcitabinebased chemotherapy. Mol Cancer Ther 2011;10:1993-9.

19. Ogura T, Yamao K, Hara K et al. Prognostic value of K-ras mutation status and subtypes in endoscopic ultrasound-guided fine-needle aspiration specimens from patients with unresectable pancreatic cancer. J Gastroenterol 2013;48:640-6.

20. Shin SH, Kim SC, Hong SM et al. Genetic alterations of K-ras, p53, c-erbB-2, and DPC4 in pancreatic ductal adenocarcinoma and their correlation with patient survival. Pancreas 2013;42:216-22.

21. Franko J, Krasinskas AM, Nikiforova MN et al. Loss of heterozygosity predicts poor survival after resection of pancreatic adenocarcinoma. J Gastrointest Surg 2008; 12: 1664-72; discussion 72-3.

22. Da Cunha Santos G, Dhani N, Tu D et al. Molecular predictors of outcome in a phase 3 study of gemcitabine and erlotinib therapy in patients with advanced pancreatic cancer: National Cancer Institute of Canada Clinical Trials Group Study PA.3. Cancer 2010;116:5599-607.

23. Ikeda N, Nakajima Y, Sho M et al. The association of K-ras gene mutation and vascular endothelial growth factor gene expression in pancreatic carcinoma. Cancer 2001;92:488-99.

24. Kwon MJ, Jeon JY, Park HR et al. Low frequency of KRAS mutation in pancreatic ductal adenocarcinomas in Korean patients and its prognostic value. Pancreas 2015:44:484-92

25. Lee J, Jang KT, Ki CS et al. Impact of epidermal growth factor receptor (EGFR) kinase mutations, EGFR gene amplifications, and KRAS mutations on survival of pancreatic adenocarcinoma. Cancer 2007;109:1561-9.

26. Oh DY, Lee KW, Lee KH et al. A phase II trial of erlotinib in combination with gemcitabine and capecitabine in previously untreated metastatic/ recurrent pancreatic cancer: combined analysis with translational research. Invest New Drugs 2012:30:1164-74.

27. Salek C, Minarikova P, Benesova L et al. Mutation status of K-ras, p53 and allelic losses at $9 p$ and $18 q$ are not prognostic markers in patients with pancreatic cancer. Anticancer Res 2009; 29: 1803-10.

28. Kinugasa H, Nouso K, Miyahara K et al. Detection of K-ras gene mutation by liquid biopsy in patients with pancreatic cancer. Cancer 2015.

29. Talar-Wojnarowska R, Gasiorowska A, Smolarz B et al. Clinical significance of K-ras and c-erbB-2 mutations in pancreatic adenocarcinoma and chronic pancreatitis. Int J Gastrointest Cancer 2005;35:33-41.

30. Chen $\mathrm{H}, \mathrm{Tu} \mathrm{H}$, Meng ZQ et al. K-ras mutational status predicts poor prognosis in unresectable pancreatic cancer. Eur J Surg Oncol 2010;36:657-62.

31. Yamada T, Nakamori S, Ohzato $\mathrm{H}$ et al. Detection of K-ras gene mutations in plasma DNA of patients with pancreatic adenocarcinoma: correlation with clinicopathological features. Clinical cancer research: an official journal of the American Association for Cancer Research 1998;4:1527-32

32. Dabritz J, Preston R, Hanfler J, Oettle H. Follow-up study of K-ras mutations in the plasma of patients with pancreatic cancer: correlation with clinical features and carbohydrate antigen 19-9. Pancreas 2009:38:534-41.

33. Liu SX, Xia ZS, Zhong YQ. Gene therapy in pancreatic cancer. World journal of gastroenterology 2014;20:13343-68.

34. Miura Y, Ohnami S, Yoshida K et al. Intraperitoneal injection of adenovirus expressing antisense K-ras RNA suppresses peritoneal dissemination of hamster syngeneic pancreatic cancer without systemic toxicity. Cancer letters 2005;218:53-62

\section{Submit your next manuscript to BioMed Central} and we will help you at every step:

- We accept pre-submission inquiries

- Our selector tool helps you to find the most relevant journal

- We provide round the clock customer support

- Convenient online submission

- Thorough peer review

- Inclusion in PubMed and all major indexing services

- Maximum visibility for your research

Submit your manuscript at www.biomedcentral.com/submit 